\title{
Lecturas de Freire
}

\section{Adriana Puiggrós*}

En este texto se examinan las ideas de Paulo Freire a través de la visión expresada por otros autores en una selección de prólogos de sus libros y de polémicas. Estos textos se han convertido en una producción con sentidos propios y distintos, en ocasiones disidentes. Se revisa el prólogo de Erari María Fioria a Pedagogía del oprimido; el de Julio Barreiro a La educación como práctica de la libertad; el prólogo de Freire a Educación como praxis política de Francisco Gutiérrez; así como las entrevistas de Ricardo Kotscho a Paulo Freire y Frei Betto y la de Carlos Alberto Torres a Freire. La lectura de estos textos proporciona nuevos ángulos desde los cuales analizar el mensaje freireano. Se examina la incidencia de las ideas iniciales del educador brasilero, se analiza el tránsito de su obra y se los confronta con la impronta actual del neoliberalismo en la educación.
Palabras clave

Alfabetización

Pedagogía

Oralidad

Relación educación-

política

Inédito viable

* Profesora investigadora de la Universidad de Buenos Aires (Argentina). Doctora en Pedagogía. Líneas de investigación: historia de la educación; políticas educativas; alternativas pedagógicas; pedagogía latinoamericana. Publicación reciente: (2020), "Balance del estado de la educación en época de pandemia en América Latina: el caso de Argentina", en I. Dussel, P. Ferrante y D. Pulfer (comps.), Pensar la educación de tiempos pandemia: entre la emergencia, el compromiso y la espera, Buenos Aires, UNIPE, pp. 33-42. CE: adriana.puiggros@gmail.com 


\section{INTRODUCCIÓN}

El centenario del nacimiento de Paulo Freire ha convocado a numerosas universidades, escuelas, sindicatos docentes, educadores populares, e incluso gobiernos, a recordar al educador brasileño y a presentarlo a las nuevas generaciones. Ofrecer a Freire y su obra y escribir prólogos de sus libros se ha constituido, desde hace tiempo, en una producción que tiene un sentido propio. Podría decirse que Freire adquirió una postura especular que incita a la reflexión, que orienta a muchos autores a trazar líneas de identificación, o bien a manifestar críticas, siguiendo su consejo. Por otra parte, Paulo mantuvo algunas polémicas que conservan actualidad e incluso impactan sobre el presente.

Cada uno de los textos surgidos como prólogos, introducciones o alocuciones, así como las opiniones vertidas en conversaciones con el autor, producen intervenciones en su legado. En ocasiones se trata del subrayado de algunas de sus ideas, o del elogio de su prolífera producción; también hay interpretaciones de conceptos, y en otras oportunidades se trata de afirmaciones que producen inquietud, generan sensaciones de falta, de imposibilidad de cierre, de rebelión frente a gestos de clausura del pensamiento freireano. Esta última acción, no la rebelión sino el intento de oclusión, la reverencia que coloca al otro en un lugar pontificado que resulta inalcanzable para los mortales, la sumisión que esconde distanciamiento, e incluso borramiento del autor que ha muerto, no es lo mismo que la ceremonia de despedida que Freire merece.

Desde los lejanos años de su trabajo con los campesinos en Recife, Paulo tuvo muchos interlocutores, discípulos y contrincantes. En 1964 estaba rodeado de enemigos, adversarios e indiferentes: el régimen militar de su país lo quería preso, y su pensamiento se iba desprendiendo del discurso internacional "políticamente correcto" en el que habitaba la Alianza para el Progreso y en cuyos programas había trabajado. Al mismo tiempo, la izquierda brasilera lo rechazaba duramente, acusándolo de desconocer la categoría "clases sociales" y, en general, los conceptos del marxismo.

Afortunadamente Paulo tenía amigos, entre los cuales destacaban los gobiernos de Perú, Bolivia y Chile, colegas vinculados a la teología de la liberación, el Consejo Mundial de Iglesias y el naciente movimiento de educadores populares. En las universidades latinoamericanas su obra se empezaría a leer alrededor de 1970; para entonces el campo freireano se había ensanchado considerablemente. Sus libros empezaban a traducirse a varios idiomas y la izquierda había terminado por aceptarlo (a mediados de los ochenta pudo viajar por primera vez a Cuba). Las interpretaciones de sus conceptos se multiplicaron en el interior de las comunidades de base y de los movimientos de liberación. Los organismos internacionales realizaban una tarea de selección que retrotraía al Freire de la etapa desarrollista y ofrecía una lectura posible que disimulaba lo disruptivo. Su trabajo fue reducido a un método de alfabetización, educación de adultos, educación para sectores marginados y a la didáctica; sus reflexiones, utilizadas para 
atenuar el autoritarismo de los sistemas escolares o para enfrentar a la educación pública y, más cerca de la actualidad, fueron usadas a favor de la "neoliberalización" de la educación.

Distintos intereses y perspectivas teóricas y políticas incorporan pensamientos de Freire; ocurre que una obra "trascendente" (en el sentido freireano del término) no puede reducirse a algunas verdades. Esa imposibilidad es probablemente el origen de su carácter universal.

\section{HorizonTES DE UN MÉTODO DE ALFABETIZACIÓN}

Uno de los primeros prólogos de libros de Paulo Freire fue escrito por el profesor Erari María Fiori. Filósofo defensor de la democracia, Fiori debió dejar su Brasil natal para refugiarse en Chile, donde tuvo una actuación destacada como vicerrector de la Universidad Católica. Fiori exaltaba la participación estudiantil en la gestión universitaria y rechazaba el argumento conservador de que los jóvenes no están preparados para comprender y resolver problemas académicos y administrativos. Se les debía devolver la palabra. Autor de trabajos sobre metafísica y política, e interesado en el contenido político de las utopías, no podía dejar de entusiasmarse con el pensamiento de Freire.

Uno de los puntos de mayor interés en la semblanza de Pedagogía del oprimido que escribió Fiori en 1970 es que intuye que el trabajo de su compatriota trasciende la alfabetización, aunque aún lo sigue considerando un "método". Así, la pedagogía de Freire es un método de alfabetización cuya "idea animadora” abarca toda la dimensión humana de la educación como "práctica de la libertad". Pedagogía y antropología se vinculan y el humanismo orienta la política. Alfabetización deviene en concientización. Las "técnicas de alfabetización" del método Freire no responden a criterios técnico-pedagógicos, sino que se unen en la praxis de la concientización. Fiore ve en Freire a un educador humanista que "al inventar sus técnicas pedagógicas, redescrubre a través de ellas el proceso en qué y por qué se constituye la conciencia humana" (Fiori, 2005: 12).

Fiori toma las categorías fundamentales del libro que prologa. Opone la pedagogía del opresor a la pedagogía del oprimido, la educación que practican los dominadores a la educación liberadora; desarrolla ampliamente el concepto de concientización. Asimismo, aprehende la idea de "trascendencia” (que es estructural en la construcción teórica de Freire). Interpreta el sentido de la "palabra generadora" que, desde su sentido inicial, trasciende, tiene la potencia de generar otras cuando parte del universo cultural del educando. La propia experiencia representada en cuadros, diapositivas y otros materiales disponibles permiten que el educando comience a decodificar, reflexionar y abrirse más allá: "lo que antes era enclaustrado, poco a poco se va abriendo" y cita a Freire: "la conciencia pasa a escuchar los llamados que la convocan siempre más allá de sus límites: se hace crítica" (Fiori, 2005: 14). La conciencia crítica tiene la capacidad de atravesar situaciones que pretenden enclaustrarla, distanciarse del mundo, volver sobre 
situaciones pasadas, objetivarlas, someterlas a juicio. Es conciencia del mundo, reflexión sobre la praxis, historización. Entonces Fiori concluye en que el método de alfabetización de Freire es un método de concientización.

\section{UN PENSAR EN CONTINUO MOVIMIENTO}

La edición de La educación como práctica de la libertad, publicada por la editorial Tierra Nueva en 1970, fue una de las primeras obras de Freire conocidas. En el prólogo, el escritor uruguayo Julio Barreiro pregunta qué entendemos por educación en una América Latina signada por la desigualdad y el analfabetismo y hace suyas las ideas de Freire: "la educación verdadera es praxis, reflexión, y acción del hombre sobre el mundo para transformarlo" (Barreiro, 1997: 7). Barreiro advierte que plantear la transformación del mundo llevada a cabo por el pueblo es "convulsionar el orden anacrónico en que todavía nos movemos” (Barreiro, 1970: 7). Lo más interesante del prólogo de Barreiro es que, en coincidencia con Pierre Furter, subraya la importancia de la comunicación en el pensamiento de Freire. La escritura del brasilero es expresión de su oralidad, del diálogo con otro. Esa observación nos remite, como luego veremos, a la escena de Frei Betto reconstituyéndose en la oralidad, que supone algún tipo de interlocución.

El prologuista observa que para Freire las ideas de libertad, justicia e igualdad deben estar encarnadas en la realidad de quien las enuncia. Señala dos enlaces opuestos de esos términos: como enmascaramiento de la cultura decadente o como instrumento de transformación; el objetivo de la práctica educativa es la libertad. Barreiro se refiere al trabajo de alfabetización de Freire que asombró en los años sesenta, cuando lograba que un campesino adulto se alfabetizara en 45 días. Es importante que el educador uruguayo no reduce la acción alfabetizadora a un ingenioso método de enseñanza, sino que destaca que el alumno se ha hecho "dueño de su propia voz", que alcanzó a decir y escribir su propia palabra (Barreiro, 1970: 10). Sin embargo, todavía se refiere a la obra que está empezando Freire como un método de alfabetización, aunque con el rasgo original de calar en lo profundo de la cultura popular.

Barreiro retoma la información a la que ha hecho mención el sociólogo brasilero Francisco Weffort en su prólogo a la primera edición de $L a$ educación como práctica de la libertad (Freire, 1969). El llamado "método freireano" se extendió rápidamente por el país desde las ciudades al campo; se crearon "círculos de cultura", la campaña llegó de manera relativamente espontánea a millones de brasileros. Establece una diferencia entre la concepción ingenua del analfabetismo, que lo considera una mala hierba que debe ser erradicada, un mal de nuestros pueblos, y aquélla que propone abordarlo como un fenómeno que refleja la estructura de la sociedad. Esta distinción radical en la concepción del analfabetismo obliga a cambiar el método y los materiales de trabajo. Como no se trata de depositar palabras, hay que descartar los antiguos silabarios, que responden a la idea de domesticación. La intimidad entre aspectos conceptuales y materiales del 
proceso de enseñanza/aprendizaje, que observa Barreiro, cobran más interés a la luz de la actual discusión sobre la incidencia de la tecnología.

Barreiro rescata que Freire se opone a la idea ingenua de alfabetización, que esconde el "miedo a la libertad" (referencia al texto de Erick Fromm, leído y citado por Freire). Aquella noción de la alfabetización produjo búsquedas de tecnologías eficientes que nunca lograron triunfar. En cambio, la alfabetización integrada a la lucha por la libertad ha tenido resultados maravillosos. En América Latina abundan las experiencias.

\section{LA PRAXIS COMO PUNTO DE ENCUENTRO}

Freire también escribía prólogos. En 1982 lo hizo para un libro de Francisco Gutiérrez, filósofo inscrito en la teología de la liberación, aunque también influido por las corrientes antiinstitucionales de los años sesenta y setenta. El prologuista cuenta que conoció a Gutiérrez 12 o 13 años antes, en Lima. La lectura de su primer libro le dejó una buena impresión

... a pesar de la ingenuidad, por mí antes cometida, de discutir la educación sin percibir que, al hacerlo, no es posible escapar de las cuestiones del poder... Una cosa me parecía todavía bien clara y perceptible en el primer libro de Gutiérrez: la insatisfacción del autor de cara a ciertos análisis que hacía, a lo cual juntaba el coraje de correr riesgos en la búsqueda de su propia superación (Freire, 1984: 7).

Freire dice que, como a él mismo le ha ocurrido, Gutiérrez tuvo en su escrito inaugural una ingenuidad que no revelaba la esperteza de quienes insisten en la neutralidad de la pedagogía, de los que diluyen todo en "el bien general de la humanidad”. Destaca que, en su nuevo libro, Gutiérrez vincula educación y política, tiene un alto nivel de criticidad, "experimenta, como tal vez no se ha hecho hasta ahora, lo dialéctico entre la denuncia y el anuncio" (Freire, 1984: 8). Freire recomienda Educación como praxis política como un libro "para ser estudiado, y no simplemente leído" (Freire, 1984: 8). Freire y Gutiérrez se encuentran en el concepto de "praxis". Gutiérrez cita una ponencia que presentó Freire en el Simposio Internacional de Alfabetización realizado en Persépolis, Brasil, en 1975: "Así, cuando hablo de la mujer y el hombre me estoy refiriendo a seres históricos, y no a abstracciones ideales. Hablo de seres cuya conciencia está íntimamente ligada a su vida real y social" (Gutiérrez, 1984: 74).

Según Gutiérrez, la educación no debe partir de un hombre abstracto. Hay que reflexionar; los educadores deben reflexionar, puesto que su opción y su compromiso desembocan en la práctica. Al hacerlo sobre la propia, encontrarán su "razón existencial" y su "compromiso como sujetos de la historia que tienen la obligación de transformar por su acción creadora", y nuevamente cita a Freire en Persépolis: "La práctica de pensar la práctica es la mejor manera de aprender a pensar recta y correctamente" (Gutiérrez, 1984: 151). Gutiérrez y Freire alientan a los educadores a abandonar el desánimo y la pasividad. Gutiérrez reproduce palabras escritas por Freire en 
1974 que exaltan la educación con cierto aire misional: el educador no debe "achacar el fracaso al sistema, a la institución y a las condiciones de trabajo" o "reducir su práctica a una carrera profesional" (Gutiérrez, 1984: 152).

La marea de aliento revolucionario de los años setenta y comienzos de los ochenta adjudica a los educadores un papel relevante en la política. Les exige que superen el activismo, que asuman como finalidad de la educación la transformación de la conciencia, para transformar la sociedad.

\section{ENTRE LA DOCTRINA Y LA LIBERTAD}

Frei Betto escribe El día de Angelo P. y vuelca en el papel sus propias vivencias como preso de la dictadura militar (1969-1973). Angelo-Betto observa a la élite de los presos comunes con los cuales ha convivido: adoptan la actitud de los policías. Es lo que Paulo Freire nos dice en una de sus obras; la "capacidad del sistema en inyectarse en la gente". Pienso que "el mayor desafío del proceso pedagógico es hacer que la cabeza del oprimido no sea más hotel del opresor” “¡Eso!”, contesta Paulo en el diálogo que mantienen en octubre de 1984 (Frei Betto, 1987: 101).

Nada, ni ruidos, ni olores ni luces provienen del mundo exterior; sólo por la mañana los ruidos del cuartel. Frei Betto compara la completa soledad de Angelo (la propia) con Robinson Cruzoe, quien tenía la suerte de estar junto a Viernes. Al náufrago de la obra de Daniel Defoe

...no le habría dado envidia la situación del prisionero, reducido a su propio cuerpo y lo que dentro de él había. Allí [en la cárcel] no había nadie que le reflejara la identidad, hechos que le subrayaran el sentido de la existencia u objetos que le tradujesen la familiaridad con el mundo. Estaba solo como la Luna en noche de tempestad (Frei Betto, 1987: 54).

Angelo-Betto atraviesa los momentos más oscuros hasta que descubre la posibilidad de hablar en soledad con alumnos imaginarios. Era un tiempo "en que era arriesgado conjugar los verbos en futuro. En él residía vivo, aunque apocado, el niño que gusta de soñar utopías" (Frei Betto, 1987: 60).

Frei Betto menciona la ansiedad, los sueños, las oraciones de los presos cuando se acerca el momento de su salida. Freire dice que él también conoció esa situación: "de repente el mundo se estrecha de tal manera que la tendencia es atravesar sus fronteras por medio de la imaginación”. Ambos pensadores reflexionan sobre la imaginación. El dominico dice que su preocupación era cómo contenerla, pues solía dispararse hacia abismos; por eso la trató de disciplinar con las clases en voz alta. "¿Vio Betto- le dice Paulo- cómo, en el fondo, un gesto profundamente lúcido puede parecer un pensamiento loco?” - Betto: “زexactamente! El teniente pensó que yo me había vuelto loco más rápido de lo que esperaba, porque todo el día hablaba solo, hablaba, cantaba..." (Frei Betto, 1987: 113-114).

Frei Betto le pide a Freire que se extienda sobre el sueño y la pesadilla, tema que ya ha mencionado. Freire dice que lo primero es plantearse si el 
sueño es "históricamente viable"; luego qué lapso de tiempo y espacio será necesario transitar para hacerlo realidad, y si ese lapso es muy extenso, aprender a caminar y "caminando, reaprender inclusive a realizar el sueño, es decir, buscar los caminos del sueño" (Frei Betto, 1987: 148). Freire no cree que haya futuros sin sueños posibles y recuerda una anécdota: "Amílcar Cabral cerró los ojos y comenzó a hablar sobre la futura Guinea-Bisau libre. De pronto un militante le dijo: - ¡Camarada Cabral, esos son sueños! Cabral respondió: -Claro que son sueños. Pobre de la revolución que no sueña..." (Frei Betto, 1987: 158).

Ricardo Kotscho, el entrevistador de Paulo y Betto, hace una última pregunta: “¿cómo ve cada uno de ustedes las cosas antes de cerrar los ojos y soñar?": Freire sueña con "una sociedad con sus calles y sus plazas siempre llenas de pueblo", que no se vacíen nunca más, que los líderes políticos no se sirvan de ellas para negociar hacia arriba; sueña con que todos los brasileros aprendan a transformar el país, a no disociar transformación revolucionaria y democracia; sueña con "una sociedad reinventándose de abajo hacia arriba donde las masas populares tengan, de verdad, el derecho a tener voz y no apenas el deber de escuchar" (Frei Betto, 1987: 158).

Frei Betto sueña con un futuro de la sociedad latinoamericana que logre "recrear un estilo propio de vivir la experiencia de la fe cristiana, esa nueva iglesia que está surgiendo y de vivir la experiencia de la construcción del socialismo". Y cita a Freire: "donde la exigencia de justicia no signifique ninguna limitación de la libertad, y la plenitud de las libertades no signifique ninguna restricción del deber de justicia” (Frei Betto, 1987: 158).

En el diálogo entre Freire y Frei Betto hay una tensión característica de la época. Hay una "verdad", la concepción dialéctica de la historia, pero no hay que "convencer", "es que no quiero convencerlos, no quiero ningún proceso educativo que resulte una peluca. Tiene que ser cabello"-dice Frei Betto. "Yo lo diría más radicalmente, Betto - interviene Freire - es como demostrarle al educando que, tratando de convencerlo, uno vive el convencimiento como una victoria con y no una victoria sobre él" (Frei Betto, 1987: 137).

\section{EL “INÉDito ViABLE”}

Freire lucha con las "verdades", las que provienen de su raíz católica y las que le impone el marxismo que va incorporando. Se interpone el personalismo de Emmanuel Mounier, que impide el cierre doctrinario de la persona, a la cual ese autor describe libre en la elección de los valores y creativa. La lectura de Mounier y la interpretación existencialista del catolicismo de Jacques Maritain abonan a la intuición freireana de la posibilidad de la creación cultural dentro del vínculo pedagógico. Algo es nuevo, desconocido; es posible lo original, el futuro no está escrito.

La investigadora Lidia Rodríguez plantea que el "inédito viable" freireano "es quizás una de las categorías más interesantes; se refiere a la capacidad creadora, que se activa a partir del reconocimiento de la posibilidad de superar las 'situaciones límite"' (Rodríguez, 2015: 159). Freire dice que en 
estas situaciones se encuentran razones para la esperanza y la desesperanza y que es "una de las tareas del educador o educadora progresista, a través de un análisis político serio y correcto, descubrir las posibilidades —cualesquiera que sean los obstáculos- para la esperanza" (Rodríguez, 2015: 159). Y enfatiza las bases ético-históricas de las acciones motivadas por la esperanza, esa acción política.

El otro aspecto a considerar en la categoría "inédito viable" es la necesaria convicción prospectiva del educador, su esperanza de futuro, de continuidad de la historia. Sólo dando una oportunidad a la historia se justifica la identidad del educador. Se trata de un principio que tiene particular actualidad. Las grandes corporaciones, invasoras del escenario educativo, erigidas en educadoras desde hace unas décadas, han advertido que en el trabajo educativo está una de las llaves para el dominio del futuro; han identificado a los alumnos como clientes y a los docentes como sus empleados. No es solamente tras las ganancias inmediatas (enormes durante la pandemia) que las trasnacionales tecnológicas ofrecen plataformas, contenidos enlatados, programas de evaluación productores de ranking, sino que se proponen ocupar los lugares que han dejado vacíos o insuficientemente atendidos los sistemas de educación pública. Saben que la viabilidad de la dominación político-educativa de las grandes mayorías reside allí.

En términos freireanos, el programa pedagógico de las corporaciones consiste en la "domesticación" de las masas, en la "alienación" del pueblo. Se trata de convertir humanos en "hombres-objeto" (y aunque Freire no se haya referido a los problemas de género, subrayamos el peso del término patriarcal), en lugar de "hombre-sujeto" (diremos humanes bajo sujeción). Para la persona despojada de subjetividad no existe nada inédito que pueda ser viable desde su propia praxis. Ésta ha sido reducida a la práctica programada por otros.

Es en la lógica del "inédito viable" que tenemos que encarar los retos que se nos presentan en la educación. El punto de partida es la propia "praxis" (usando el término del educador brasilero) siendo conscientes y valorando las experiencias pedagógicas democrático-populares estatales, las de los educadores y los educandos en las aulas, en los hogares, en los libros, los cuadernillos, las reuniones virtuales, las redes, las comunicaciones radiofónicas y tantas otras que son problematizadas por el interrogante de Alicia de Alba sobre la "presencialidad" en la "virtualidad" (De Alba, 2021). La autora abre varios interrogantes y motiva a encararlos desde ángulos inéditos.

\section{Otra PEDAgogía ES POSIBLE}

Por supuesto, Freire fue cambiando y enriqueciendo sus ideas a lo largo de los años. En una entrevista que le realizara Carlos Alberto Torres cuando Paulo era funcionario, dijo:

...hoy, soy secretario de Educación de la ciudad de São Paulo con una claridad y una comprensión política y pedagógica mucho mayores, espero, que cuando 
tenía 30 o 35 años de edad. Veo la situación más claramente ahora y me siento más radical, pero jamás sectario, en relación a la realidad de mi país (Torres, 1997: 47).

Como ocurre con la mayoría de los intelectuales, en el andamiaje teórico de Freire una idea fuerza se sostuvo siempre y es la que está contenida en el título de su segundo libro. En la mencionada entrevista, Torres le pregunta a Freire “¿cuál es la historia que hay detrás de Pedagogía del oprimido, vista en perspectiva, 20 años después?”. Freire dice que, en primer lugar, él escribe sobre lo que hace, que produjo este libro en el exilio, aprendiendo a vivir en una realidad ajena, donde comenzó a evaluar su práctica anterior, en Brasil y en Chile: "La Pedagogía del oprimido surgió como una necesidad práctica y teórica de mi carrera profesional”. Freire considera que se trata de uno de sus mejores títulos, que surgió como una "necesidad de enfatizar la existencia de otra pedagogía", que pretendía distinguir de la "pedagogía del opresor”. Quería, según entiendo, correr la cortina que oculta a esta última, nombrándola sin subtítulos, en toda su crudeza, al destacar la existencia de otra pedagogía posible (quizás en el momento de dar nombre a su libro, Freire ya estaba gestando "una pedagogía de la esperanza"). En la misma entrevista, el autor dice que le preocupa llamar la atención sobre "el papel de sujeto en contraposición al de simple protagonista de las clases trabajadoras en busca de su propia liberación” (Torres, 1997: 43).

Otra pedagogía contiene para Freire una noción de los sujetos pedagógicos que reconoce la heterogeneidad social y la diversidad cultural. El concepto de educación dialógica no podría evadir la cuestión del multiculturalismo, así como de la implicación de este tema en la política. Torres señala el interés de Freire por la capacitación ciudadana para el ejercicio de sus derechos democráticos. Es interesante que el autor analiza el tránsito de Freire desde la consideración de la educación como un factor instrumental destinado a construir la conciencia crítica, hasta la afirmación de su carácter profundamente político. Freire "era plenamente consciente de las implicaciones políticas de una educación liberadora”, así como de sus contradicciones. A lo largo de su producción, la educación va perdiendo el carácter instrumental: Freire afirma que "no hay revolución educativa que pueda provocar una revolución del poder” (Torres, 2001: 210).

\section{FREIRE, ILICH Y LA LIBERTAD}

En los años sesenta dos educadores protagonizaron posturas críticas de la educación tradicional en América Latina. Eran antagónicas y tuvieron serias consecuencias en las décadas siguientes. La polémica que mantuvieron aquellos autores guarda plena actualidad.

Paulo Freire aportó la crítica que más rédito ha dejado en vistas a producir alternativas al sistema escolar latinoamericano. Su denuncia constituyó una ruptura epistemológica con la posición del sujeto pedagógico de la modernidad, acompañada por un imaginario pedagógico que aún tiene valor como base de nuevos programas educativos. Debe anotarse que Freire 
dirigió su crítica a la relación pedagógica entre educadores y educandos de una manera general, es decir, con categorías aplicables no únicamente a los educadores y educandos escolares, sino a todos los vínculos pedagógicos. Desde las primeras propuestas, dirigidas a los analfabetos y los adultos en grupos populares, fue extendiendo el campo de su teoría, valorizando la acción de la escuela y los docentes, hasta llegar a su cargo en el gobierno de la ciudad de São Pablo.

Freire formó numerosos discípulos que derivaron en un amplio espectro de posiciones. En sus extremos se ubicaron grupos políticos diversos, desde quienes redujeron la idea de la "palabra generadora" a una serie doctrinaria, hasta quienes la interpretaron como un método de enseñanza que aplicaron en programas de orientación asistencialista. Sin embargo, las principales ideas del brasilero permearon la formación de los educadores latinoamericanos, especialmente después de la caída de las dictaduras militares de la región. La interioridad entre educación y política, la oposición entre la educación basada en el diálogo y en el reconocimiento del otro, y la educación "bancaria"; la misión emancipadora de la educación, la alfabetización como un instrumento político educativo, la prioridad del pueblo como sujeto de la educación, son ideas que conservan su vigencia. Freire desarrolló categorías que ponen en crisis el discurso educativo neoliberal, aunque fueron concebidas años antes de que el mercado se instalara como un actor preponderante y prepotente en el campo de la educación.

Es distinto lo que ocurrió con las ideas del sacerdote tercermundista Iván Illich, quien dirigía en México el Centro de Investigación y Docencia de Cuernavaca (CIDOC), y se hizo famoso por su producción a favor de la desescolarización, que consideraba el proceso idóneo para revolucionar la sociedad opresora. El más difundido de sus textos fue "Esa vieja y gorda vaca sagrada”, discurso que pronunció desde los balcones del Palacio Quemado, sede del gobierno nacional de Bolivia, en ocasión de la asunción presidencial del general Juan José Torres, en 1970. Los maestros, una de las principales fuerzas que llenaban la plaza apoyando al presidente electo, fueron alentados por Illich a abandonar las escuelas para liberar de esa manera la educación. Illich proponía desmontar el aparato escolar, así como el sistema público de salud, y promovía la sustitución de los profesionales en educación por activistas culturales que se desplegaran en un campo pedagógico informal.

La institución educativa es atacada en la actualidad en todos sus frentes, y las ideas de Iván Illich sirven de sustento a quienes sostienen que la figura del docente carece de actualidad. Opciones tecnológicas, sumadas a un activista cultural que requiere escasa preparación, serían una buena manera de sustituir maestros y escuelas. Debe anotarse que este tipo de propuestas, lejos de estar solamente en la imaginación de algunos autores, constituyen uno de los más concretos programas que circulan en el mercado.

Mientras las ideas de Illich son bienvenidas por el neoliberalismo, ha sido un hecho significativo que el ultraneoliberal presidente de Brasil, Jair Bolsonaro, haya desplazado, prohibido y censurado las ideas, libros y 
enseñanzas de Paulo Freire. Esa reacción demuestra que el autor de Educación como práctica de la libertad sigue aportando a ese último término significados que renuevan a la educación su potencial emancipador. La utopía liberadora de la educación freireana sólo arraiga en una política democrática.

\section{Palabras finales}

Paulo Freire es un autor que ha sido ampliamente estudiado, citado, entrevistado. Aportó ideas que abrieron perspectivas para la educación desde ángulos diversos: epistemológico, antropológico, político. Uno de sus aspectos más notables es la capacidad de configuración de una praxis, suceso que requiere del enlace del pensar con el hacer. Freire tenía una particular capacidad de comprensión de las situaciones políticas y sus futuros probables. Supo conocer al educando sin confundirlo con el educador, a la vez que entendió que ambos adquieren existencia en el vínculo. Concibió como posibilidad que esa relación fuera liberadora porque creía profundamente en la libertad como fundante de lo social. Su concepto de libertad es de especial importancia frente al uso degradado de este término en el marco de la educación neoliberal. Libertad para Freire es emancipación, es el sueño de Frei Betto, de las experiencias populares de educación; es la esperanza en la acción política que lo motiva a aceptar la dirección de un sistema escolar. La personalidad y la obra de Freire abren innumerables interrogantes para la investigación y la acción.

\section{REFERENCIAS}

Barreiro, Julio (1997), "Educación y concienciación", en Paulo Freire, La educación como práctica de la libertad, México, Siglo XXI, pp. 7-19.

De Alba, Alicia (2021), "La construcción de la presencialidad en la virtualidad como exigencia político pedagógica", Revista Argentina de Investigación Educativa, año 1, núm. 1, pp. 13-29.

FioRI, Ernani María (2005), "Aprender a decir su palabra. El método de alfabetización del profesor Paulo Freire", en Paulo Freire, Pedagogía del oprimido, México, Siglo XXI, pp. 11-27.

Frei Betto (1987), El día de Angelo P. Un clamor de justicia, Buenos Aires, Dialéctica.

Freire, Paulo (1969), Educação como prática da liberdade, Río de Janeiro, Paz e Terra.

Freire, Paulo (1970), La educación como práctica de la libertad, Montevideo, Tierra Nueva.

FreIre, Paulo (2005), Pedagogía del oprimido, México, Siglo XXI.

Freire, Paulo (1984), "Prólogo", en Francisco Gutiérrez, Educación como praxis política, México, Siglo XXI, pp. 7-8.

GutiérreZ, Francisco (1984), Educación como praxis política, México, Siglo XXI.

Rodríguez, Lidia Mercedes (2015), Paulo Freire. Una biografía intelectual. Surgimiento y maduración de la pedagogía del oprimido, Buenos Aires, Colihue.

Torres, Carlos Alberto (1997), Pedagogia da luta. Da pedagogía do oprimido á escola pública popular, São Paulo, Papirus.

Torres, Carlos Alberto (2001), Democracia, educación y multiculturalismo, México, Siglo XXI. 